\title{
IMPACT OF PHEROMONE TRAP DESIGN, PLACEMENT AND PHEROMONE BLEND ON CATCH OF POTATO TUBER MOTH
}

\author{
T.J.B. HERMAN ${ }^{1,2}$, J.R. CLEARWATER ${ }^{3}$ and C.M. TRIGGS ${ }^{4}$ \\ ${ }^{1}$ Crop \& Food Research, PO Box 85, Hastings, New Zealand \\ ${ }^{2}$ Current address: Fruitfed Supplies, PO Box 322, Hastings, New Zealand \\ ${ }^{3}$ Clearwater Research and Consulting, 63 Peter Buck Rd, Auckland, \\ New Zealand \\ ${ }^{4}$ Department of Statistics, University of Auckland, Private Bag 92019, \\ Auckland, New Zealand
}

Corresponding author: therman@fruitfedsupplies.co.nz

\begin{abstract}
Potato tuber moth (Phthorimaea operculella (Zeller)) (PTM) is an important pest of potatoes in New Zealand. Pheromone traps are used to monitor potato tuber moth populations in the field to help time insecticide applications. Two experiments assessed the effect of pheromone blend, trap design and trap height on the capture of potato tuber moths. Water traps caught the most moths per day, but took longer to service. 'DeSIRe' sticky traps (delta-shaped) caught more moths than 'A-trap' sticky traps (cylinder-shaped) and funnel traps. The 1:1 and 1:1.5 pheromone blends caught more moths than the 1:4 blend. Trap height had no significant effect on moth catch. It is concluded that the DeSIRe sticky trap is the most suitable for commercial use. The 1:1.5 pheromone blend is recommended for commercial use as it is increasingly being used in New Zealand and overseas.

Keywords: potato tuber moth, Phthorimaea operculella, pheromone traps, pest monitoring.
\end{abstract}

\section{INTRODUCTION}

Pheromone traps have become an important tool for monitoring pest populations in a range of crops. Traps baited with a species-specific sex pheromone capture males from field populations. Trap design, placement of the trap and ratio of the chemical components of the pheromone can all produce big differences in the number of moths caught (e.g. Herman et al. 1994).

The potato tuber moth is an important pest of potatoes in New Zealand because of its high reproductive potential and the inability of insecticides to prevent tuber infestation (Foot 1979). This generates a need for a monitoring system to optimise pest control before tubers are infested.

Two chemicals have been identified as the components of the potato tuber moth sex pheromone, (E4,Z7)-tridecadienyl acetate (PTM 1) (Roelofs et al. 1975) and (E4,Z7,Z10)-tridecatrienyl acetate (PTM 2) (Persoons et al. 1976). These two chemicals were synthesised (Voerman \& Rothschild 1978) and blends ranging from 9:1 to 1:9 tested (Voerman \& Rothschild 1978; Raman 1988). Most blends of the two chemicals were effective in catching male potato tuber moths.

Both Raman (1988) and Tamhankar \& Harwalkar (1994) tested a water trap and a funnel trap and found no significant difference in moth catch. However, Bacon et al. (1976) found water traps caught more moths than sticky traps. While Raman (1988) concluded that potato tuber moth pheromones could be an extremely useful tool in a 
potato tuber moth IPM programme, the research cited above showed that a number of trap-related factors can influence the catch of moths. These results from overseas may not hold for New Zealand.

Two experiments were set up to compare four trap designs, two trap heights and three ratios of the two pheromone chemicals using a Latin square design (Perry et al. 1980).

\section{MATERIALS AND METHODS}

Two experiments were conducted in 1 ha of potatoes, cv. Rua, at Crop \& Food Research's Pukekohe Research Station. The potatoes, planted in early November, were under standard management practices, except no insecticides were applied. The potato plants were at full cover at the first experiment (3-14 February 1997) and were lodging when the second experiment was run (18-30 March).

Both experiments were laid out as a 12 x 12 Latin square - 12 days by 12 trap positions (Perry et al. 1980). For each experiment a line of traps at $9 \mathrm{~m}$ spacing was placed at right angles to the predominant wind direction (west). The 12 treatments of each experiment occurred once in each line. Male moths caught in the preceding night were counted and removed each day. The position of each treatment was re-randomised each day, with each treatment being located at each of the 12 positions in the line for one night.

In Experiment I, two types of pheromone trap, DeSIRe sticky trap (HortResearch) and funnel trap (Agrisense), three pheromone blends, 1:1, 1:1.5 and 1:4 (PTM 1:PTM 2, total $0.2 \mathrm{mg}$ loading) (HortResearch), and two trap heights (the level of the pheromone lure), 0.3 and $1 \mathrm{~m}$, were tested in a complete 3-way factorial design.

In Experiment II, three types of pheromone trap, DeSIRe sticky trap (tested at 0.3 and $1 \mathrm{~m}$ ), 'A-trap' sticky trap (Ciba) (0.3 m) and a water trap (Bacon et al. 1976) (on the ground), and the same three pheromone blends used in the first experiment were tested. On one date the time to service a water trap compared with a sticky trap was recorded.

As the data from both experiments were in the form of counts, they were transformed to a log scale and analysed in a generalised linear model. Values and standard errors presented are back-transformed from the log scale.

\section{Experiment I}

\section{RESULTS}

The DeSIRe traps caught an average of 17.1 moths/trap/day, which was more than 8 times the 2.1 moths/trap/day caught in the funnel traps $(\mathrm{P}<0.001, \mathrm{SED}=0.75)$. Observations made one evening during the trial were that moths attracted to the funnel traps tended to land on the prominent rim of the trap with only a third entering the trap (J.R. Clearwater, unpubl. data).

There was a significant difference $(\mathrm{P}<0.001)$ in the effectiveness of the different ratios of pheromone components but this was not consistent between the two trap heights tested (Table 1). In the traps set at $1 \mathrm{~m}$ above the ground there was no difference between the 1:1 and $1: 1.5$ blends $(\mathrm{P}=0.58)$, but at $0.3 \mathrm{~m}$ there was a very significant difference $(\mathrm{P}=0.002)$. The 1:4 blend, on average, caught fewer moths than the other two blends.

There was no significant difference in moth catch between the two trap heights.

TABLE 1: Capture of potato tuber moths using three blends of pheromone components and in traps held at two heights in Experiment $I$.

\begin{tabular}{|c|c|c|c|c|c|}
\hline \multirow[b]{2}{*}{ Trap height (m) } & \multicolumn{3}{|c|}{ Pheromone blend (PTM1:PTM2) } & \multirow[b]{2}{*}{ Mean } & \multirow[b]{2}{*}{$\mathrm{P}$-value } \\
\hline & $1: 1$ & $1: 1.5$ & $1: 4$ & & \\
\hline 0.3 & 8.4 & 12.9 & 8.7 & 10.0 & $\mathrm{P}=0.002$ \\
\hline 1.0 & 10.9 & 11.4 & 5.4 & 9.2 & $\mathrm{P}=0.58$ \\
\hline Mean & 9.7 & 12.2 & 7.0 & & $\mathrm{P}<0.001$ \\
\hline
\end{tabular}




\section{Experiment II}

The performance of the three types of pheromone trap tested in this experiment differed significantly $(\mathrm{P}<0.001)$ (Table 2$)$. The water trap caught an average of $124 \mathrm{moths} /$ trap/day, which was four times more than that of the DeSIRe trap (29.3 moths/trap/day) and almost 15 times more than the A-trap (8.3 moths/trap/day).

There was no difference in moth catch in traps baited with the 1:1 and 1:1.5 pheromone blends and they both outperformed the 1:4 pheromone blend, with moth catch being greater for the 1:1 and 1:1.5 blends for the DeSIRe and water traps. There was little difference between the three blends for the A-Trap.

There was no significant difference in moth catch in the DeSIRe traps at $0.3 \mathrm{~m}(29.3$ moths/trap/day) and $1.0 \mathrm{~m}$ (29.7 moths/trap/day).

The time taken to service the two types of traps was measured once during this experiment. It took 6 minutes to count and remove 153 moths caught in a water trap compared with 10 seconds for the 23 moths in a DeSIRe trap.

TABLE 2: Capture of potato tuber moths in three types of pheromone traps baited with three blends of pheromone components in Experiment II.

\begin{tabular}{lrrrr}
\hline & \multicolumn{3}{c}{ Pheromone blend (PTM1:PTM2) } & SED \\
\cline { 2 - 4 } Trap type & $1: 1$ & $1: 1.5$ & $1: 4$ & 3.4 \\
DeSIRe $^{1}$ & 32.8 & 33.3 & 22.2 & 2.4 \\
A-trap & 9.1 & 8.2 & 7.5 & 9.7 \\
Water & 124.3 & 127.0 & 116.0 & \\
\hline Mean & 49.8 & 49.4 & 42.0 & \\
\hline
\end{tabular}

${ }^{1}$ mean of both trap heights

\section{DISCUSSION}

Of the three pheromone trap components studies, trap design had a greater impact on PTM catch than the ratio of pheromone chemicals and trap height. The lower catch of moths in the funnel traps was due to the design of the trap. The funnel traps are more effective at catching larger moths, e.g. noctuids (Herman et al. 1994), and are not suitable for smaller gelechiids.

The water traps captured four moths for every one taken by the best sticky trap (DeSIRe). This result is very similar to the results of Bacon et al. (1976), Keerati-Kasikorn (1981) and Salas et al. (1991). Tamhankar \& Harwalkar (1994) reported that funnel traps (different design to that tested here), on average, caught more moths than water traps, although the difference was not significant. They also noted variation in trap catch was greater for the water traps. While the water trap has a high saturation point in terms of the number of moths it can catch, the efficiency of the water trap may decline in hot dry weather as the water evaporates. Tamhankar \& Harwalkar (1994) found that water level, relative to the pheromone lure, was a critical factor affecting trapping efficiency of water traps in the laboratory.

Experience has shown that the effectiveness of the sticky bases, such as those used in the DeSIRe trap, decreases when 20 or more moths have been caught (J.R. Clearwater, unpubl. data). If the bases are not changed at this point, the trap catch of the sticky traps will decline. Of the two sticky traps evaluated in these experiments, the DeSIRe traps caught more moths than the A-traps. These results are similar to those of Kennedy (1975) who evaluated a range of sticky traps for catching PTM in California. Sticky traps of a 'delta' design similar to the DeSIRe trap were generally better at catching moths than cylindrical traps with a design similar to the A-traps. 
An issue with the water trap is that it took more time to service, mainly because there were more moths to count. One way around this would be to develop a volumetric method to measure the depth of wet moths in a container, but this would be less accurate than an absolute count. The low moth catch in the A-trap lowers the sensitivity of this trap in identifying changes in the PTM population, making it less suitable for monitoring.

The preference for the 1:1 and 1:1.5 blend over the 1:4 blend seen in these two experiments reflects the results reported by Voerman \& Rothschild (1978) in Australia. Their traps captured a mean of 932 males with the $1: 1,1041$ with the 1:1.5, and 658 with the 1:4 blend (differences not significant). Raman (1988) reported no statistical difference between $1: 1$ and $1: 1.5$ blends (4.15 and 4.52 moths/trap/day, respectively). While there is little difference between the $1: 1$ and $1: 1.5$ blends, the $1: 1.5$ blend is increasingly being used commercially and should continue to be used in the future.

Both trap heights $(0.3$ and $1.0 \mathrm{~m})$ were equally effective in capturing male moths. Moths were observed approaching traps, flying in erratic short hops between leaves on the top of the potato plants. They were well placed to fly straight into DeSIRe traps placed $0.3 \mathrm{~m}$ high. However, the higher traps were entered just as readily, with the moths making a rapid climb to the level of the higher $1 \mathrm{~m}$ traps when 1-2 m away. Kennedy (1975) found that traps at $0.3 \mathrm{~m}$ caught more males than traps at $1.0 \mathrm{~m}$, but also reported wide variation in the data. Raman (1988) found no differences between three heights, ground level, 0.4 or $0.8 \mathrm{~m}$.

In conclusion, the DeSIRe sticky trap (delta trap design) is the preferred type of pheromone trap to use in a PTM monitoring system. The fluctuations in the moth catches in this trap reflect the population of PTM in the crop and they are easy and quick to service. There was no clear difference between the 1:1 and 1:1.5 ratios, but the latter is recommended as it is already in use commercially in New Zealand and overseas. Since trap catches were similar at both heights tested, the traps are probably best located at the top of the canopy (and raised or lowered as the foliage grows and senesces) for ease of locating and accessing in the field.

\section{ACKNOWLEDGEMENTS}

Thanks to Philip Kirsch, IPM Technologies, Oregon, USA, for supply of A-traps.

\section{REFERENCES}

Bacon OG, Seiber JN, Kennedy GG 1976. Evaluation of survey trapping techniques for potato tuberworm moths with chemical baited traps. Journal of Economic Entomology 69: 569-572.

Foot MA 1979. Bionomics of the potato tuber moth, Phthorimaea operculella (Lepidoptera, Gelechiidae), at Pukekohe. New Zealand Journal of Zoology 6: 623-636.

Herman TJB, Cameron PJ, Walker GP 1994. Pheromone trap colour and field position effects on the catch of tomato fruitworm moths and bumble bees. Proceedings of the 47th New Zealand Plant Protection Conference: 154-158.

Keerati-Kasikorn M 1981. Initial studies towards the implementation of a pest management system for the control of the potato tuber moth (Phthorimaea operculella Zeller) in south-eastern Queensland. Ph.D. thesis, University of Queensland, Australia.

Kennedy GG 1975. Trap design and other factors influencing capture of male potato tuberworm moths by virgin female baited traps Journal of Economic Entomology 68: 305-308.

Perry JN, Wall C, Greenway AR 1980. Latin Square designs in field experiments involving insect sex attractants. Ecological Entomology 5: 385-396.

Persoons CJ, Voerman S, Verwiel PEJ, Ritter FJ, Nooijen WJ, Minks AK 1976. Sex pheromone of the potato tuberworm moth, Phthorimaea operculella: Isolation, identification and field evaluation. Entomologia Experimentalis Applicata 20: 289-300. 
Raman KV 1988. Control of potato tuber moth Phthorimaea operculella with sex pheromones in Peru. Agriculture, Ecosystems and Environment 21: 85-99.

Roelofs WL, Kochansky JP, Carde RT, Kennedy GG, Henrick CA, Labovitz JN, Corbin VL 1975. Sex pheromone of the potato tuberworm moth, Phthorimaea operculella. Life Science 17: 699-706.

Salas J, Alvarez C, Parra A 1991. Evaluacion de dos componentes de la feromona sexual, tres disenos y altura de colocacion de treampas en la eficiencia de atraccion y captura de adultos machos de Phthorimaea operculella. Agronomia Tropical 41: 169-178.

Tamhankar AJ, Harwalkar MR 1994. Comparison of a dry and a water trap for monitoring potato tuber moth Phthorimaea operculella Zeller. Entomon 19: 163-164.

Voerman S, Rothschild GHL 1978. Synthesis of the two components of the sex pheromone system of the potato tuberworm moth, Phthorimaea operculella (Zeller) (Lepidoptera: Gelechiidae) and field experience with them. Journal of Chemical Ecology 4: 531-542. 